Receb ido: 10/07/2016

Aprovado: 05/09/2016

\title{
A escrita de si em The Handmaid's Tale, de Margaret Atwood: limites e possibilidades na relação entre narrativas ficcionais e a ciência histórica
}

Isabela Gomes Parucker

Resumo: $O$ presente trabalho objetiva contribuir para as discussões acerca da escrita da história, a partir da reflexão sobre os usos de narrativas ficcionais em processos de subjetivação e construção identitária, dando enfoque à mulheres. Examinando a obra de ficção da autora canadense Margaret Atwood, procuro pensar as potencialidades da escrita literária na ciência histórica e suas possíveis interconexões.

Palavras-chave: Ficção; Escrita de si; História.

Abstract: This paper aims to contribute to the discussions on the writing of History regarding the uses of fictional narratives in processes of subject-formation and constructing identities, focusing on women. By examining Canadian author Margaret Awtood's fictional work, I ponder on the potential of literary writing in History and their possible interconnections.

Keywords: Fiction; Self writing; History.

\footnotetext{
Mestranda em História - Programa de Pós-graduação em História - Departamento de História - Universidade de Brasília, Distrito Federal - Brasil. Bolsista Cnpq.
} 


\section{Introdução}

Falar da descoberta e (re)invenção do eu implica levantar questionamentos acerca da consciência dos sujeitos, de identidade, da relação que as pessoas estabelecem com o mundo (entre outros e consigo). A possibilidade da tomada de consciência de si, de nossa existência enquanto sujeitos, pode decorrer do contato com o outro, num exercício de alteridade, em que reconhecemos o diferente e podemos conhecer a nós mesmos. Pode também ser desdobramento de viagens e devaneios próprios, de experiências subjetivas que nos levam a perceber nossa singularidade, nossa experiência própria enquanto indivíduos existentes no mundo. Dar forma a essa descoberta é uma maneira de trazer para uma realidade tangível e inteligível aquilo que nos torna humanos e sujeitos. Podemos, portanto, construir identidades por meio de representações. Em diálogo com as ideias de Foucault, a autora Margareth Rago trabalha a "escrita de si" (RAGO, 2003: 52) como um processo de subjetivação, ou seja, um movimento pelo qual os indivíduos podem tomar consciência do seu próprio existir, ou entender-se como sujeitos no mundo, num tempo. Essa escrita de si é também forma de se pensar uma representação da experiência individual e, assim, é parte de processos de construção identitária.

A história é também uma representação de experiência e da própria existência humana. Pois além de sua dimensão empírica - dos acontecimentos, da ação no tempo-, a história tem também a qualidade de uma ciência, que ocupa-se não apenas na investigação de documentos, como também na reflexão sobre a condição humana e na elaboração de narrativas que possam explicar essa experiência. Na ciência histórica, os historiadores, motivados por carências de orientação na vida prática (RÜSEN, 2001: 35), lançam seu olhar para o passado, num esforço de dar sentido a inquietações e reflexões que surgem em seu presente. Guiados por ideias, métodos e fundamentações teóricas, constroem narrativas que reúnem o que se conhece sobre os acontecimentos pretéritos e as conclusões de sua pesquisa, por meio da qual eles, no presente, podem dar significados ao passado e se orientar para o futuro. Cria-se, assim, um diálogo entre as dimensões temporais passado-presente-futuro, no qual os historiadores operam como mediadores, articulando espaço de experiência e horizonte de expectativa (KOSELLECK, 2006: 31). A elaboração da narrativa historiográfica, forma de apresentação do trabalho da ciência histórica à qual se recorre mais comumente, constitui a associação entre acontecimentos passados, presentes em vestígios e registros da ação humana no tempo (suas fontes), e uma trama desenvolvida pelo historiador. Nela, eles interpretam as fontes, analisam

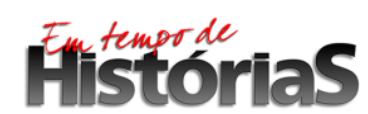


as informações de que dispõem (em procedimentos metodologicamente controlados), e as relacionam com aquilo que já se escreveu sobre elas, dialogando com teses, teorias e conclusões de seus pares.

A história foi, entretanto, por muito tempo (e ainda é, de certa forma), centrada na ideia de um sujeito humano universal, sem uma diferenciação da participação e experiência dos dois sexos (FACINA; SOIHET, 2012: 9). A historiografia dominante - marcada por essa tradição iluminista do sujeito humano universal - inevitavelmente, privilegia o masculino, deixando de lado ou mesmo invisibilizando uma série de outros sujeitos, dentre eles as mulheres.

No exitoso esforço de fazer um apanhado da renovação historiográfica e dos movimentos feministas a partir da década de 1960, Rachel Soihet e Adriana Facina (2012) apontam para as contribuições que ambos os fenômenos trouxeram para a história das mulheres. Nesse panorama, observam que a ideia do sujeito na historiografia e na própria história passou a ser repensada, pois houve uma "pressão bem-sucedida das historiadoras feministas a fim de realizar revisões de uma história que, centrada na noção de sujeito universal, manteve experiências de outros sujeitos, em particular das mulheres, em vastas áreas de invisibilidade" (FACINA e SOIHET, 2012: 15). Estudos decorrentes das conquistas e demandas dos movimentos feministas trouxeram, assim, questionamentos acerca de estruturas que a história naturalizou, mas que são, de fato, históricas. Hierarquias e relações de gênero baseadas na ideia de dominação e subordinação passaram a ser problematizadas num esforço de desconstrução de paradigmas e reelaboração de narrativas historiográficas mais inclusivas e igualitárias. Um exemplo dessa tentativa é a obra de Michelle Perrot (1988), "Os excluídos da história", a qual dedica um capítulo às mulheres e repensa as representações feitas delas e de seus poderes, ao mesmo tempo em que problematiza a própria ideia de poder (no singular, no sentido de uma figura central) e como ela é tradicionalmente associada ao masculino (PERROT, 1988: 167). Essas representações e ideias naturalizam um modelo patriarcal que hierarquiza as relações de gênero e marginaliza - quando não exclui - diversos grupos da qualidade de sujeitos da história. Dessa forma, a busca pela (re)construção e recuperação de uma memória feminina tem vistas à reinserção desses sujeitos que experimentam e fazem a história.

Esse esforço não se deu, contudo, sem obstáculos. A escassa presença das mulheres em registros do passado nas esferas pública, principalmente, e privada da vida dificultam jogar luz sobre a experiência do passado para, com isso, dar a ela sentidos (FACINA e 
SOIHET, 2012: 15). O tornar-se sujeito na história e da história, para mulheres, foi (é) um processo mais difícil e não tão acessível quanto para os homens. É possível, ainda assim, encontrar vestígios do passado de diversas maneiras, em formas variadas.

As cartas e os diários íntimos são exemplos de outros registros femininos que, quando encontrados, são da maior importância para descortinar o universo feminino. (...) As obras literárias e a escrita religiosa - católica ou protestante - também aparecem como formas significativas de expressão feminina. (FACINA e SOIHET, 2012: 15).

Nesse sentido, em vista da marginalização a que, por muito tempo, foram submetidas as mulheres na história e pelo necessário esforço em refletir sobre formas diversas de representação e inscrição de sua experiência no tempo, é fundamental pensarmos a literatura, a narrativa ficcional como forma legítima de se registrar experiências e realidades, como uma escrita de si, e como meio de dar sentido à ação humana no tempo. Ela configura um veículo de comunicação, um mecanismo possível para as mulheres escreverem sobre sua própria existência, bem como um meio de se investigar sobre a própria condição humana no tempo, como faz a história.

Sob o risco de cair no conhecido debate sobre as fronteiras entre história e literatura, o que objetivo aqui é, portanto, colaborar num debate acerca da validade de se trabalhar com a narrativa ficcional como forma de se contar e elaborar histórias, memórias e identidades. Embora tenha a consciência de que tal problema não será de maneira alguma encerrado no presente artigo, ofereço uma contribuição para que se possa pensar o próprio fazer história. Partindo da fecunda proposição de Reinhardt Koselleck de que a teoria da história configura uma investigação das condições das possibilidades de existência da história (KOSELLECK, 2014: 93) - tanto no âmbito da experiência quanto do conhecimento -, tento compreender, sobretudo, como histórias podem ser examinadas, narradas e representadas. Nesse sentido, a teoria da história configura espaço para indagações também acerca de temas e campos que fazem parte da experiência humana tanto quanto do próprio ofício do historiador (a noção tempo, de poder, a questão do sujeito, relações de gênero).

Analisando uma obra ficcional de 1985, The Handmaid's Tale (A História da Aia, título em português $)^{1}$, da autora canadense Margaret Atwood, proponho, então, uma reflexão acerca da relação entre escrita de si, história e ficção. Procuro pensar a importância de

\footnotetext{
${ }^{1}$ Para o presente trabalho, utilizei a edição de 1998 da editora Anchor Books, Nova York. Cf.: ATWOOD, Margaret. The Handmaid's tale. New York: Anchor Books, 1998.
} 
narrativas ficcionais nos processos de subjetivação e construção de identidades para mulheres, na investigação e representação de sua experiência.

\section{Ficção e história na construção de narrativas}

Somos seres de linguagem, usamo-la para nos relacionar com os outros, com o mundo, com nós mesmos (GADAMER, 2014: 113). É pela linguagem que mediamos e representamos nossa experiência no tempo, é com ela que dialogamos com nosso contexto, e é por meio dela que podemos interpretar e compreender o mundo, por meio das repreensões que com ela fazemos. A ficção é um meio para se brincar com e testar a linguagem que é, por sua vez, um "instrumento de nomeação dos elementos do universo humano" e "tem estatuto instituinte da realidade histórica" (LACERDA, 1994: 29). Ainda que sua preocupação em ater-se a critérios de veracidade seja diferente daquela da escrita historiográfica, é possível compreender a narrativa ficcional como uma forma de se escrever um tipo de história, uma vez que tem o poder de nomear e criar representações, trazendo à realidade elementos do nosso universo.

Há, nessa perspectiva, afinidade entre a composição histórica e a ficcional (LACERDA, 1994: 38). Essas narrativas têm uma formulação semelhante em termos de escrita e têm uma mesma atribuição; tanto uma quanto a outra "dão ordem e sentido a uma massa de 'dados' cujo significado prévio é distinto do que lhes é atribuído na composição" (LACERDA, 1994: 34). Ambas têm a mesma matéria: lidam com a realidade, cada qual à sua maneira e com suas estratégias, sua linguagem e seus estilos, e pensam a condição e a experiência humana no tempo. Além disso, por muitas vezes ter como base (seja em termos de reprodução, questionamento ou inspiração) modelos, estruturas, códigos e experiências reais - e, consequentemente, históricas -, a ficção é capaz também de (re)produzir e representar realidades ${ }^{2}$, e tem grande potencial transformador (LACAPRA, 1989: 4-5). A narrativa ficcional pode, portanto, ser uma forma de se representar experiências, ou seja, de

\footnotetext{
${ }^{2}$ Faço uso aqui da ideia de Ulpiano de Meneses de que a representação é uma necessidade incontornável, pois precisamos dela para tornar nosso mundo inteligível e a ele dar sentido. Meneses afirma que "representamos o mundo para torná-lo inteligível. O mundo tal como é seria um enigma indecifrável se não pudesse ser reconstruído pelas formas que criamos para entender as formas incriadas e criadas. (...) Ficção, portanto, não se opõe a verdade: designa as figuras (palavra da mesma família) que modelamos, para darmos conta da complexidade e vastidão infinitas do mundo." MENESES, Ulpiano T. Bezerra de. "O museu e questão do conhecimento". In: GUIMARÃES, Manoel Luiz Salgado Guimarães; RAMOS, Francisco Régis Lopes (orgs.). Futuro do Pretérito: Escrita da História e História do Museu. Fortaleza: Instituto Frei Tito de Alencar; Expressão Gráfica Editora, 2010, p. 20.
} 
nomeá-las. Ao dar nome e forma às coisas, podemos conhecê-las. É, pois, pela representação que podemos tornar o mundo inteligível. ${ }^{3}$

Se pensarmos então que a narrativa ficcional, assim como a história, tem a qualidade de nomear experiências e contar verdades (LACERDA, 1994: 38-39), estaremos diante da constatação de que a ficção é um instrumento poderoso para escritas de si. Considerando, ainda, as particularidades de uma escrita de si feminina, — não num sentido de haver uma "essência feminina", mas naquele que atenta para as especificidades da experiência vivida por mulheres em sociedades predominantemente patriarcais e masculinas ${ }^{4}$-, percebemos que a literatura é um espaço bastante profícuo para a prática de inscrever-se no mundo e de refletir sobre o próprio existir para as mulheres.

Ao nomear experiências, a narrativa ficcional é capaz de trazê-las à realidade. Cria, assim, um canal de comunicação e, consequentemente, um meio para se conhecer o mundo (ou um mundo). Ela permite também grande liberdade para criação, para testar os limites da linguagem, criar metáforas, produzir imagens, situações, cenários que jogam com o real e o imaginário. É capaz de gerar, então, novas possibilidades de escritas de si, uma vez que há maneiras diversas de traduzir em palavras a experiência subjetiva do indivíduo que a linguagem do cotidiano - pretensamente neutra, mas tendo como referência o masculino nem sempre dá conta de expressar. A subjetividade das pessoas, das mulheres, no caso, encontra na escrita ficcional tanto um espaço para sua vivência quanto um veículo para sua expressão. É pertinente, nessa perspectiva, trabalhar a partir da ideia de escritas de si como processos contínuos em de representação de verdades subjetivas por meio de linguagem. Abre-se espaço para a subjetividade na análise histórica, para um exercício de compreensão do si mesmo, num esforço de esclarecer - não apenas para os outros, mas, sobretudo, para nós mesmos - quem somos em determinado momento, como nos entendemos no mundo, como percebemos nossos modos de existir.

\section{A História da Aia}

\footnotetext{
${ }^{3}$ Representar é tornar inteligível, como afirma Ulpiano Meneses. Idem, ibidem.

${ }^{4}$ A afirmação da consagrada escritora inglesa Virginia Woolf, ao falar sobre a escrita como profissão para mulheres, que diz fazer parte da atividade de toda escritora "matar o anjo do lar", é um dos inúmeros exemplos da especificidade da experiência feminina. Woolf caracteriza esse tal anjo como um fantasma que constantemente, durante o processo de escrita, faz questão de lembrar as mulheres de tudo o que elas não podem falar, pensar, sentir, de como devem se comportar e de que maneira devem escrever. Mostra, assim, como os obstáculos colocados a processos de subjetivação para as mulheres começam no seu interior, em decorrência de processos históricos e culturais que construíram hierarquias, papeis sociais e estruturas de poder desiguais, que se manifestam e têm efeitos diferentes de acordo com o gênero dos indivíduos. Cf.: WOOLF, Virginia. Profissões para mulheres e outros artigos feministas. Porto Alegre: L\&PM, 2012, pp. 11-14.
} 
As experiências e subjetividades representadas pela e na ficção são, muitas vezes, partilhadas e compartilhadas, como A História da Aia, de Margaret Atwood, faz tanto no nível ficcional quanto no real. Com uma longa e prestigiosa carreira, a autora canadense ${ }^{5}$ conta com mais de quarenta obras em seu currículo. Escreveu livros de poesia, literatura infantil, ficção e não-ficção, romances, e ensaios sobre a escrita como ofício, em que aborda os mais variados temas. Tem como característica de sua escrita grande delicadeza e sensibilidade para tratar dos conflitos internos de suas personagens, como é o caso d'A História da Aia. Atwood dá bastante atenção a reflexões sobre questões como o tempo, a existência, a condição humana.

O livro A História da Aia está entre suas obras mais conhecidas e aclamadas, e é bastante marcado por esses traços da escrita da autora. Esse romance distópico conta a vida de Offred, uma mulher da República de Gilead, regime totalitário instaurado após um golpe de grupos de uma extrema direita fundamentalista nos limites do que outrora se conheceu como os Estados Unidos da América. A obra é apresentada como conjunto de relatos e lembranças da personagem principal, que descreve sua experiência como mulher numa sociedade em que os indivíduos do sexo feminino eram divididos em castas e a elas eram designadas funções bastante específicas, vinculadas basicamente ao trabalho doméstico ou à reprodução/procriação.

No livro, Offred, a personagem principal, realiza um movimento de encontro com e reelaboração de seu eu por meio de suas lembranças e da narrativa que constrói a partir daquilo que vive e sente. De forma não linear, Offred remonta sua história, voltando ao passado e comparando-o com o seu presente. Conta sobre como viu seus direitos sendo gradualmente cerceados, como viu-se assimilando e naturalizando aos poucos os valores do sistema que a aprisionava. Relembra o dia em que o dinheiro que tinha passou a ser propriedade de seu marido, tirando dela sua autonomia. Recorda o momento em que perdeu sua filha para o Estado, pois não se enquadrava no padrão de mulheres aptas a terem a guarda de crianças ${ }^{6}$. Revive seus dias no Centro Vermelho, o centro de treinamento para as aias ${ }^{7}$, onde eram ensinadas as doutrinas do regime de Gilead e afirmava-se sua importância no

\footnotetext{
5 Informações sobre a autora Margaret Atwood estão disponíveis no sítio eletrônico http://margaretatwood.ca/biography/ Acesso em 26 de abril de 2016.

${ }^{6}$ Havia diversas razões para as mulheres não serem consideradas aptas a ter a guarda de crianças, mesmo que fossem seus próprios filhos. No caso de Offred, ela não era tida como apta pois não era a primeira esposa de seu marido e, ao que se pode inferir da trama, havia tido com ele uma relação extraconjugal durante o primeiro casamento deste.

${ }^{7}$ As aias, na trama, são as mulheres férteis, aptas a gerar filhos. Elas passavam por uma espécie de treinamento no qual eram levadas a internalizar os valores e as lógicas sociais - a organização, as hierarquias e os papéis de cada indivíduo - daquela nova sociedade. Apenas os indivíduos que detinham maior poder político e econômico dispunham de aias em seus núcleos domésticos.
} 
reequilíbrio e reestruturação da sociedade. Lembra de como aprendeu sobre as responsabilidades atreladas à sua função naquela sociedade (aia), sobre como deve ser sua conduta. Recorda também sobre como foi levada a internalizar a ideologia e os ideais do sistema. Incorpora a lógica do regime e os argumentos que são usados para legitimá-lo. Offred questiona o sistema e, ao mesmo tempo, vê-se parte dele.

Em uma passagem emblemática, vemos o conflito da protagonista ao perceber que passara a acreditar em algo que consideraria absurdo e opressor no passado. Ao deparar-se com um grupo de estrangeiros, entre eles mulheres - com sorrisos grandes e saias curtas -, Offred comenta que as mulheres em Gilead deixaram de vestir roupas tão reveladoras como aquelas há um longo tempo. Ela e Ofglen, sua companheira de caminhadas ${ }^{8}$, sentem fascínio e repulsa pela cena:

"I stop walking. Ofglen stops beside me and I know that she too cannot take her eyes off these women. We are fascinated, but also repelled. They seem undressed. It has taken so little time to change our minds, about things like these.

Then I think: I used to dress like that. That was freedom."

(ATWOOD, 1998: 28).

Offred reconhece que naturalizou valores e comportamentos do regime, e refere-se à sua vida anterior como liberdade. Após a instauração da ditadura teocrática gileadiana, as mulheres perderam sua autonomia. As mulheres dessa sociedade, em especial as aias, passaram a ter uma vida rigorosamente controlada; sua rotina, seu comportamento, sua biologia. As liberdades dessas mulheres foram gradualmente cerceadas. Suas possibilidades de escolha, da simples escolha de roupas à escolha entre ser mãe ou não, desapareceram.

E embora acabe assimilando muito do regime, Offred resiste solitária e silenciosamente; seus pensamentos, suas lembranças, sua memória são suas e ela se esforça para registrá-las de alguma maneira, para que ela não seja apagada, para o mundo e para si. Sua liberdade está no seu interior, na sua subjetividade.

A trama do livro é, em si, um retrato de uma escrita de si: conta a vivência de uma mulher, mostra como ela se inscreve no mundo, se torna sujeito, se torna real (ainda que tudo conspire para que ela seja invisível, seja um objeto). Offred assume controle da própria vida, dentro do campo de possibilidades e liberdade do qual dispõe, num esforço de reinvenção e reformulação sua própria subjetividade. Torna-se, à sua maneira, autora "do próprio script" (RAGO, 2003: 52).

\footnotetext{
${ }^{8}$ As aias de Gilead só podiam sair de casa acompanhadas de outras aias, em duplas.
} 
A obra é também, como descobrimos ao final do livro, um exercício fictício da ciência histórica, quando as memórias da personagem são transformadas, por historiadores, em fonte para a construção de um narrativa historiográfica numa investigação sobre a ação humana em um tempo (passado). Cria-se sentidos e significados para sua experiência por meio da análise, interpretação e compreensão dos registros e vestígios por ela deixados. O posfácio - não por acaso intitulado Historical Notes - apresenta o trabalho de reconstrução da história de Offred e de Gilead, a explicação dos eventos, a representação de uma experiência pretérita, a composição de uma narrativa (histórica) que dá sentido a um passado. Neste capítulo, aprendemos também que Offred escapou da casa do comandante de quem era aia, e conseguiu registrar sua experiência ao contar suas memórias. Não se sabe que fim levou a personagem; contudo, a partir dos relatos por ela deixados após sua fuga, foi possível remontar o cenário do momento em que ela viveu, e com isso, analisar os acontecimentos que a cercaram, as situações que ela experimentou. Num trabalho de pesquisa histórica, examinaram as fontes os relatos e lembranças deixados por Offred -, interpretaram seus significados e puderam, então elaborar uma narrativa histórica que desse sentido aos eventos do passado em que viveu a personagem, traçando também os contornos de seu contexto. As memórias de Offred se tornaram material tanto para a formulação de representações de um passado quanto para o reconhecimento e entendimento da sua própria existência.

\section{Um exercício de escrita de si}

A escrita de si enquanto processo de subjetivação pelo ato próprio da escrita é uma forma de representar memórias, de construir identidades. A leitura, por sua vez, é o processo no qual se realiza a escrita pois é nela que se concretiza o potencial semântico do texto pela apropriação da narrativa ${ }^{9}$, na qual quem lê tem acesso ao seu eu e ao mundo por meio da interpretação. A leitura é, portanto, parte da escrita de si e leva-a ainda além, transformando-a em escrita de todos, em escrita coletiva. Pois, como sugere Umberto Eco, a narrativa é um universo aberto (ECO, 2005: 45); são infinitas as possibilidades de interconexões que os intérpretes podem descobrir num texto. A escrita de si elaborada pela autora torna-se também uma escrita coletiva quando é lida. Ainda, a leitura de textos permite o conhecimento do eu

\footnotetext{
${ }^{9} \mathrm{~A}$ ideia trabalhada por Chartier de que ler é uma "apropriação do texto" é um diálogo com a tese de Paul Ricoeur. Cf.: CHARTIER, Roger. "Textos, impressão, leituras". In: HUNT, Lynn (org.). A nova história cultural. São Paulo: Martins Fontes, 2001, p. 215.
} 
(CHARTIER, 2001: 215). Nesse sentido, o registro de uma experiência feminina em forma de narrativa ficcional, mesmo que não submetida ao rigor metodológico da ciência histórica, não deixa de ser uma escrita de si e uma representação de realidades, pois dá sentido a uma experiência, a uma vivência. Permite a produção de um material para a memória, para uma história. Nesse sentido, a própria ausência de um rigor metodológico e uma maior liberdade no uso da linguagem da ficção fazem com que ela possa ser uma escrita de si.

A qualidade de uma escrita coletiva também se configura quando a trama possibilita reflexões e investigações sobre a própria existência das mulheres ao apresentar estruturas de dominação e subjugação ao masculino e a um sistema patriarcal. Nessa perspectiva, as representações de uma condição feminina no livro permitem que identifiquemos circunstâncias equivalentes na história. E não é preciso ir muito longe; é possível, por exemplo, encontrar semelhanças no tratamento dado às mulheres de Gilead e a situação das mulheres no mundo ocidental contemporâneo (não apenas em 1985, quando a obra foi lançada, mas também hoje, mais de três décadas depois). A experiência descrita no livro tem, então, muito de real: hoje, no Brasil, vemos os direitos das mulheres em risco. A título de exemplo dessa situação, podemos observar o projeto de Lei 5069/13 ${ }^{10}$, aprovado no dia 21 de outubro de 2015 pelo Comissão de Constituição e Justiça (CCJ), que prevê sérias restrições na já limitada prática do aborto no país. O texto do projeto de lei, entre outros pontos, dificulta enormemente o atendimento de mulheres vítimas de violência sexual em hospitais públicos, ao exigir que elas se submetam a um exame de corpo de delito e realização de boletim de ocorrência para comprovação do abuso. Além disso, permite que os médicos se neguem a fornecer ou administrar procedimento ou medicamento que considere abortivo, como a pílula do dia seguinte, criminalizando profissionais da saúde que deem informações sobre tais métodos ou substâncias. Curiosamente, no mundo criado em A História da Aia, qualquer médico ou cientista que fizesse o mesmo também era penalizado, sendo punido com a pena de morte e tendo seus corpos expostos no Muro para servir de exemplo a todos que ousassem ir contra o regime (ATWOOD, 1998: 31-33). Vemos, numa sociedade patriarcal e machista, as mulheres serem tratadas como seres inferiores, como objeto, como propriedades. Seus corpos não lhes pertencem.

\footnotetext{
${ }^{10} \mathrm{O}$ texto completo e mais informações sobre o projeto de Lei 5069/13 estão disponíveis no sítio http://www.camara.gov.br/proposicoesWeb/fichadetramitacao?idProposicao=565882. Acesso em 23 de abril de 2016.
} 
Dessa forma, a leitura e a interpretação da obra de Atwood proporcionam a possibilidade do conhecimento do eu (de inúmeros eus). Leitores (em especial mulheres, mas não somente) podem reconhecer circunstâncias com as quais se identificam, e podem contemplar sua própria experiência. Essa narrativa ficcional se transfigura em canal para trilhar caminhos que unam o eu e o mundo, que nos façam pensar sobre e compreender nossa realidade. Se a ciência histórica é uma forma de investigar a condição humana no tempo e buscar respostas para questões do presente, para a carência de orientação na vida prática, a História da Aia é uma escrita que nos permite pensar em formas de se orientar. Ao nos apresentar uma realidade distópica, podemos refletir sobre nossas atitudes, ações políticas, comportamentos, costumes e valores de hoje. E a história, por mediar a experiência passada e projeções do futuro, nos permite levar em consideração toda a experiência que Atwood propõe. Não é uma realidade tão distante de nós.

A obra configura, portanto, uma narrativa ficcional que aparenta amalgamar tanto os aspectos da escrita de si (na trama, para a personagem, e na vida prática, para as/os leitoras/es), quanto elementos da ciência histórica. Mostra uma multiplicidade de tempos, no vai-e-vem das lembranças, nas representações do passado, nas reflexões sobre o presente, nas projeções para o futuro. Brinca com essas temporalidades no âmbito da trama e no real, pois proporciona um espaço para pensarmos sobre nossos próprios tempos. E, por ser uma distopia, é um canal bastante propício para (re)pensarmos a atualidade.

\section{Conclusão}

Voltamos, assim, à questão que deu início ao presente artigo, aquela que propõe tratar a ficção como forma de se pensar a história, em especial uma história de mulheres, sobre mulheres, feita por mulheres. Margaret Atwood produziu uma trama na qual tematiza diversas questões sobre a condição feminina numa sociedade patriarcal, machista, e conservadora. Retrata a tentativa de um sujeito feminino de fazer-se existir, inscrevendo-se no mundo e na história ao narrar sua experiência. Esses registros são fonte para a representação de uma realidade, de um passado que é feito presente, na trama, e que busca dar sentido às ações e acontecimentos humanos no tempo.

Além de fazer um jogo com temporalidades e com a própria noção de tempo, com o ir e vir das lembranças da personagem, Atwood proporciona uma reflexão acerca da condição feminina e de experiências que são, ao mesmo tempo, tão particulares e tão universais. Conta, 
dessa maneira, a história não só de uma mulher, mas de várias. Escreve e inscreve no mundo, no tempo, uma, duas, incontáveis existências femininas. Possibilita, nesse sentido, uma tomada de consciência de si. Permite a elaboração memórias, de história, de identidades e, com isso, a (re)invenção de sujeitos.

\section{Referências Bibliográficas}

ATWOOD, Margaret. The Handmaid's tale. New York: Anchor Books, 1998.

A História da Aia. (Trad. Márcia Serra). São Paulo: Marco Zero, 1987.

CERTEAU, Michel de. “A operação historiográfica”. In: . A escrita da história. Rio de Janeiro: Forense Universitária, 1982, 56-108.

CHARTIER, Roger. “Textos, impressão, leituras”. In: HUNT, Lynn (org.). A nova história cultural. 2a Ed. São Paulo: Martins Fontes, 2001, pp. 211-238.

ECO, Umberto. Interpretação e superinterpretação. São Paulo: Martins Fontes, 2005.

FACINA, Adriana; SOIHET, Rachel. Gênero e Memória: algumas reflexões. Revista Gênero, v. 5, n. 1, 2012. Disponível em: http://www.revistagenero.uff.br/index.php/revistagenero/article/download/218/142. Acesso em 5 de abril de 2016.

GADAMER, Hans-Georg. Teoria da história e linguagem: Uma réplica de Hans-Georg Gadamer”. In: KOSELLECK, Reinhart. Estratos do tempo. Rio de Janeiro: PUC-Rio/Contraponto, 2014, p. 111-118.

Estratos do tempo. Rio de Janeiro: PUC-Rio/Contraponto, 2014.

Futuro passado: contribuição à semântica dos tempos históricos. Rio de Janeiro: Contraponto: Ed. PUC-Rio, 2006.

LACAPRA, Dominick. History, politics, and the novel. Ithaca, New York: Cornell Univ Press, 1989.

LACERDA, Sônia. "História, narrativa e imaginação histórica". In: NAVARRO, Tânia. História no Plural. Brasília, Editora UnB, 1994, pp. 9-42.

MENESES, Ulpiano T. Bezerra de. "O museu e a questão do conhecimento". In: GUIMARÃES, Manoel Luiz Salgado; RAMOS, Francisco Régis Lopes (Orgs.). Futuro do Pretérito: Escrita da História e História do Museu. Fortaleza: Instituto Frei Tito de Alencar; Expressão Gráfica Editora, 2010, p. 13-49.

PERROT, Michelle. Os excluídos da história. Rio de Janeiro: Paz e Terra, 1988.

RAGO, Luzia Margareth. A aventura de conter-se: feminismos, escrita de si e invenções da subjetividade. Campinas, SP: Editora da Unicamp, 2013.

RÜSEN, Jörn. Razão histórica. Teoria da história: os fundamentos da ciência histórica. Jörn Rüsen; tradução de Estevão de Rezende Martins. $1^{\text {a }}$ reimpressão. Brasília, EdUnB, 2001.

WOOLF, Virginia. Profissões para mulheres e outros artigos feministas. (tradução de Denise Bottmann). Porto Alegre: L\&PM, 2012.

$\begin{array}{lllll}\text { Projeto de } & \text { Lei } & \text { 5069/2013. } & \text { Disponível em }\end{array}$ http://www.camara.gov.br/proposicoesWeb/fichadetramitacao?idProposicao=565882 Acesso em 23 de abril de 2016. 